\title{
AUTONOMIA DOS CONSUMIDORES NOS CONTRATOS: UMA ANÁLISE CRÍTICA E PROPOSITIVA DA CONDIÇÃO CONSUMERISTA NA CONTEMPORANEIDADE.
}

\author{
AUTONOMÍA DE LOS CONSUMIDORES EN LOS CONTRATOS: UN ANÁLISIS \\ CRITICA E PROPOSITIVA DE LA CONDICIÓN DE CONSUMIDOR EN TIEMPOS \\ CONTEMPORÁNEOS.
}

\author{
${ }^{1}$ Leonardo Macedo Poli \\ ${ }^{2}$ Sérgio Augusto Pereira Lorentino
}

\section{RESUMO}

O presente artigo é destinado ao estudo reflexivo da autonomia dos consumidores nos contratos com os fornecedores, especialmente com foco na contemporaneidade, uma vez que o período atualmente vivenciado exprime mudanças paradigmáticas sensíveis nos métodos de contrações, especialmente no que toca à condição de vulnerabilidade do consumidor, consequência da massificação dos contratos, da imposição do consumo como condição de integração social, a partir da publicidade como causa do consumismo, da descartabilidade dos bens de consumo e da perda da subjetividade nas relações entre consumidores e fornecedores. Assim, a partir de uma análise das doutrinas críticas da sociedade industrial será levado a efeito uma proposta de intervenção jurisdicional com o objetivo de proteger o sujeito consumerista, individual e coletivamente, para que se consiga estabelecer uma relação de justiça material nos contratos de consumo, capaz de atender aos princípios constitucionais brasileiros que regulam a Ordem Econômica.

Palavras-chave: Contratos, Autonomia, Contemporaneidade, Consumidor

\section{RESUMEN}

Este artículo está destinado a estudio reflexivo de la autonomía de los consumidores en los contratos con proveedores, especialmente con un enfoque en la época contemporánea, una vez que el período actualmente experimentó cambios paradigmáticos en los métodos de expresión sensible de contracciones, especialmente en lo relativo a la condición de vulnerabilidad del consumidor, debido a la masificación de los contratos, el impuesto al consumo como una condición para la integración socialde la publicidad como causa del consumismo, de la disponibilidad de bienes de consumo y la pérdida de la subjetividad en las relaciones entre consumidores y proveedores. Entonces, de un análisis de la sociedad industrial crítica doctrinas se realizará una propuesta de intervención judicial con el objetivo de proteger al consumidor, individual y colectivamente, con el fin de establecer una relación de justicia material en los contratos capaz de cumplir con los principios constitucionales brasileños que regulan el orden económico.

Palabras-claves: Contratos, Autonomía, Contemporaneidad, Consumidor

\footnotetext{
${ }^{1}$ Doutor em Direito pela Universidade Federal de Minas Gerais - UFMG, Minas Gerais, (Brasil) Email: tutortreinamento@gmail.com

${ }^{2}$ Dout orando em Direito na Pontifícia Universidade Católica de Minas Gerais - PUC Minas Gerais, (Brasil).
} 


\title{
1. INTRODUÇÃO
}

Estudar o elemento da autonomia dos consumidores nos contratos de consumo é atividade de fundamental importância para a compreensão dos problemas relacionados à justiça contratual. Isso porque o conceito do justo sempre esteve ligado à condição de governabilidade em que se encontrava o sujeito contratante para com a decisão de contratar e para com a possibilidade de construção do contrato dentro de uma ambiente de liberdade de decisão.

Dentro dessa liberdade, vital para o direito talhado nos moldes liberais, imperava o dever de respeito ao pactuado, por parte dos contratantes, mas também do Estado, na medida em que sua intervenção representaria, teoricamente, violação da liberdade e da vontade dos indivíduos. Logo, o texto do contrato deveria ser honrado tal como fosse ele o texto da própria lei (AZEVEDO, 2004, p.27). Esta premissa de respeito ao pacto significava em muito o desejo de não arbítrio por parte do Estado, afirmando a igualdade e a liberdade dos indivíduos e o respeito à suas autonomias.

Portanto, nos moldes privatistas, segundo Humberto Theodoro Junior define, as partes "podem convencionar o que quiserem e como quiserem" e isso gera força obrigacional, do que decorre o "pacta sunt servanda" (THEODORO JUNIOR, 2008, p.1).

Mas, a visão do contrato delineada na modernidade, no seio dos Estados liberais, atravessou a história e encontrou na realidade contemporânea fatores que a torna impraticável, porquanto a dinâmica das relações privadas foi severamente modificada com o advento da tecnologia da produção e da informação, fazendo com que as premissas do contrato clássico, tradicional, fundado na liberdade e na igualdade formal, com alto grau de subjetividade dos contratantes, não encontrassem referências atualmente.

Conforme anota Giovani Clark,

\begin{abstract}
$\mathrm{Na}$ "sociedade consumista", os contratos passama ser celebrados embasesdistintas dos princípios liberais do século XIX de liberdade e autonomia da vontade. Os contratos perdem a condição da prévia discussão ou negociação entre as partes (preço, forma de pagamento, prazo de entrega e etc.), mas exige apenas adesão de umdos contratantes às cláusulas e condições estipuladas ou impostas pela outraparte. (CLARK, 1994, p.37)
\end{abstract}

O fato é que as relações de consumo passaram a representar substancial fatia dos contratos privados e, cada vez mais, os regramentos e as visões que se alimentam da teoria clássico-liberal dos contratos, fundada na autonomia e na liberdade, estão em evidente crise, 
porquanto é possível a promoção de questionamentos acerca da real existência de autonomia e liberdade na contemporaneidade.

Nesse sentido emerge o questionamento de que os contratos de consumo não são expressão da autonomia, mas sim da necessidade (FIUZA, 2013, p.493). Desta forma, seria preciso um redimensionamento da teoria contratual, inclusive do paradigma atual, fundado na autonomia privada?

Aqui se situa o grande problema dos contratos de consumo, na medida em que passa a exigir, à toda evidência, uma reconstrução ou mesmo um nova construção paradigmática destinada a atender ao fenômeno social das relações contratuais de consumo, não apenas como expressão de ato volitivo, mas como compreensão do pacto como condição existencial digna dos consumidores.

Ademais, ainda que os ventos constitucionais tenham semeado no ordenamento jurídico, na doutrina e na jurisprudência novos contornos que socializaram os contratos e seus efeitos, resta uma grande tarefa a ser cumprida, qual seja a de resolver o problema que emerge da teoria geral dos contratos e dos negócios jurídicos, os quais ainda apóiam suas estruturas no elemento volitivo.

\section{OS CONSUMIDORES NA CONTEMPORANEIDADE}

Desde que a maquinofatura se impôs como meio de produção eficiente, sua evolução não parou de acontecer e encontrou no pós-guerra uma trilha ascendente com o advento de novas tecnologias produtivas, especialmente aquelas ligadas à disseminação da informação.

A condição consumerista não pode ser definida como uma evolução cultural, como acontece em outros aspectos da sociedade, a partir de um desenvolvimento histórico. Trata-se, todavia, de uma sociedade projetada, moldada e conformada para o consumo, dando vazão à toda profusão de bens que a indústria pode oferecer (BAUMAN, 2008, p.65). Talvez por isso o Direito tenha tanta dificuldades em readequar suas estruturas do século XX para os tempos atuais.

O consumidor deve, portanto, na contemporaneidade, ser um objeto de estudo das disciplinas jurídicas, especialmente aquelas ligadas ao direito privado, porque disso decorrerá conclusões apropriadas ao traçado de um novo modelo contratual em superação ao atual, até então fundado em premissas clássicas, ainda que ornamentado com algumas luzes trazidas pelos ideais de dignidade humana, da boa-fé objetiva e da função social. 


\subsection{CONSUMIDOR POR OPÇÃO?}

O tema da autonomia tem passagem obrigatória pelo estudo da condição do sujeito consumidor. Tal condição remete a uma situação de sua mais completa dependência da indústria, já que não há outro meio através do qual o consumidor consiga prover suas necessidades. Parece uma conclusão obvia e até certo ponto realmente é.

Entretanto, essa obviedade não tem sido suficiente para uma reconstrução significativa do paradigma contratual que ainda é bastante dependente dos construtos herdados dos negócios jurídicos voluntários e consensualistas.

Quando se está diante de uma condição inarredável, como é a condição de consumidor, não há o descortinar de um cenário que permita opções (autonomia), mas sim subordinação e aniquilação da liberdade.

Zygmunt Bauman, acerca da relevante ausência de opções pontua que

A "sociedade de consumidores", emoutras palavras, representaessetipodesociedade que promove, encoraja, ou reforça a escolha de um estilo de vida e uma estratégia existencial consumistas, e rejeita todas as opções cultuais alternativas. (BAUMAN, 2008, p. 71).

De fato, sem autonomia (da vontade ou privada), não há como aceitar e administrar um programa jurídico que ainda a considere existente, mesmo que em pequena monta, como tem acontecido na proposta da autonomia privada atualmente festejada e vívida nas principais normais contratuais, bem como na mais dominante doutrina e jurisprudência. Consequentemente, o primeiro passo seria o de pressupor, que, em matéria contratual de consumo, o elemento da autonomia não mais pode ser levado em conta como pressuposto de validade e muito menos de obrigatoriedade dos contratos de consumo.

Se a autonomia está fundada na liberdade e no autogoverno, nada há nada que possa sustentar sua existência (ainda que fictícia, formal) no cenário consumerista, pois ser consumidor não é opção. Como ensina Bauman, "a opção de não ir às compras não figura" entre aquelas possíveis ao consumidor (BAUMAN, 2001, p.88).

Assim, ser consumidor não é opção, bem como, por decorrência lógica, praticar atos de consumo ou atos necessários ao consumo (contratos), também não constituem fenômenos volitivos. 


\subsection{A FORÇA DA INDÚSTRIA A PARTIR DA SUA CONDIÇÃO PROVEDORA}

Na medida em que o ser humano de divorciou da natureza e de seu estado natural, foi perdendo gradativamente a capacidade de prover suas necessidades, especialmente quando se subordinou aos ditames da propriedade privada, já em fase bem adiantada da civilização humana.

Hoje, a indústria faz as vezes de natureza provedora. É dela que são colhidos todos os frutos (produtos e serviços) necessários à sobrevivência humana e isso faz da indústria um elemento completamente dominador do sujeito consumidor.

A indústria detém a propriedade da produção e de tudo aquilo que a pressupõe, desde as matérias-primas, até a propriedade das fórmulas e inventos. Até mesmo a água, elemento que mais abunda na terra, está sob a propriedade da indústria, através da titularidade de licenças de exploração ou por meio da titularidade de domínios territoriais onde florescem minas ou repousam aquíferos.

Não soará espantoso se, no futuro (próximo, talvez!), a indústria começar a envasar oxigênio para fazer face às nossas necessidades vitais de ar puro, diante da poluição atmosférica em franco curso!

De fato, não há limites para o progresso produtivo e para a apropriação de oportunidades fabris, seja com a água, como ar ou com qualquer bem que satisfaça as necessidades do homem contemporâneo.

E se é assim, não é necessário maior esforço para se inferir acerca do poder da indústria sobre as vidas dos consumidores, máxime no que toca aos negócios jurídicos necessários (contratos) à instrumentalização das relações consumeristas.

\section{O CONTRATO COMO ELEMENTO INSTRUMENTAL DO CONSUMO}

Como visto nas linhas iniciais do presente artigo, contrato, segundo a visão clássica "é um instrumento de intercâmbio econômico entre os indivíduos, onde a vontade reina ampla e livremente"(THEODORO JUNIOR, 2008, p.1).

Em geral, contratos são, para a doutrina, independente de sua gênese ou fase evolutiva "instrumentos técnicos de circulação de riquezas" (BITTAR, 2006, p.2).

$\mathrm{Na}$ esteira do pensamento mais avançado em matéria contratual, temos que contrato é

[...]ato jurídico lícito, de repercussão pessoal e socioeconômica, que cria, modifica ou extingue relações convencionais dinâmicas, de caráter patrimonial, entre duasou mais pessoas, que emregime de cooperação vis amatender desejos ou necessidades 
individuais ou coletivas, em busca da satisfação pessoal, assim promovendo a dignidade humana (FIUZA, 2013, p.494).

Diante de tais contributos é possível vislumbrar as mudanças impregnadas na evolução conceitual de contrato, sendo que a mais notável é a passagem do individualismo ao coletivismo, na medida em que o contrato não é mais um elemento afeto apenas às partes. Além disso, o contrato cumpre com a operacionalização das relações entre fornecedores e consumidores, proporcionado o acontecimento da relação de fornecimento e aquisição de produtos ou serviços.

Não obstante o fato de as relações de consumo constituírem a esmagadora maioria dos contratos havidos no cotidiano, não há uma atenção jurídico-normativa para o tema, senão a partir da aplicação de cláusulas gerais, como a da função social e a boa-fé objetiva e de alguns poucos regramentos presentes no Código de Defesa do Consumidor.

Mas, a questão de fundo dos contratos, consistente no elemento volitivo, que sempre esteve ligado à sua essência jurídica e fática, não tem recebido a atenção que se faz necessária, especialmente a partir da compreensão do sujeito consumidor da contemporaneidade, que nada se assimila com o sujeito contratante ou contatado do Estado liberal burguês.

\subsection{AUTONOMIA COMO CONDIÇÃO EXISTENCIAL DO CONTRATO}

Se contrato é um ato volitivo, liberto, decorrente da escolha consciente, qualquer ato que não expresse essas qualidades não pode ser considerado contrato. Mesmo na atualidade onde se festeja a sociabilização do contrato, ele ainda continua a ser uma decorrência da autonomia dos contratantes. É assim, por exemplo, com o princípio da liberdade contratual definido no artigo $421^{3}$, do Código Civil Brasileiro (BRASIL, Lei $\mathrm{n}^{\mathrm{o}} 10.406$, de 10 de janeiro de 2002, 2014).

Segundo Caio Mário da Silva Pereira e, de forma geral, segundo o que sempre se propagou dentro do ideal liberalista que esteve a reger o Direito Privado brasileiro, especialmente quando do advento do Código Civil de 1916, até o Código Civil de 2002, contrato pode ser compreendido como:

[...] um negócio jurídico bilateral, e de conseguinte exige o consentimento; pressupõe, de outro lado, a conformidade coma ordemlegal, sem o que não teria o condão de criar direitos para o agente; $\mathrm{e}$, sendo ato negocial, tempor escopo aqueles objetivos específicos. Com a pacificidade da doutrina, dizemos então que o contrato é um acordo de vontades, na conformidade da lei, e com a finalidade de adquirir, res guardar, transferir, conservar, modificar ou extinguir direitos. Dizendo-o mais

\footnotetext{
${ }^{3}$ A liberdade de contratar será exercida emrazão e nos limites da função social do contrato.
} 
sucintamente, e reportando-nos à noção que demos de negóciojurídico ( $n^{\circ} 82$, supra, vol. I), podemos definir contrato como o "acordo de vontades coma finalidade de produzir efeitos jurídicos" (PEREIRA, 2003, p.14).

Embora se trate de uma liberdade condicionada ao desiderato da função social do contrato são ainda, de fato, a liberdade e a autonomia, consideradas para efeitos legais de existência e validade dos contratos. Não é outro, também, o conceito doutrinário, segundo o que observa o magistério de Álvaro Villaça Azevedo, ao afirmar que "É a vontade, que, ao manifestar-se, retrata o interesse da pessoa física ou jurídica, no meio social. A vontade, assim, é autônoma ao exteriorizar-se, reafirmando a liberdade do homem na programação de seus interesses" (AZEVEDO, 2004, p.25).

Vê-se que, até aqui, tem sido defendida a inexistência de autonomia nos contratos de consumo. Portanto, para melhor estruturação da defesa de sua inexistência, importa útil um estudo pormenorizado de cada uma das vertentes da autonomia nos contratos, sendo elas a autonomia da vontade e a autonomia privada.

\subsection{AUTONOMIA DA VONTADE}

A autonomia da vontade pode ser compreendida como expressão da liberdade individual. Para Bruno Torquato, citando Francisco Amaral, "autonomia da vontade tem conotação subjetiva, psicológica" (NAVES, 2014, p.94). Para a ideologia liberal realmente os sujeitos do contrato, livres e iguais, poderiam manifestar suas aspirações.

No Brasil, a codificação contratual havida pelo Código Civil de $1916^{4}$, espelhou sem disfarces a autonomia da vontade com luminar de sua estrutura normativa. Era um Código de índole liberal, burguesa e segundo sua gênese a liberdade ocupava a função nuclear e estrutural dos contratos (BRASIL. Lei n. 3.071, de $1^{\circ}$ de janeiro de 1916, 2014).

Nesse sentido, válidas são as observações de Enzo Roppo sobre o tema, senão vejamos:

A teoria política do "contratualis mo" mostra, as sim, à evidência como o conceito de contrato pode ser utilizado, e foi historicamente utilizado, com uma função ideológica, quer dizer - uma vez que é este o significado técnico de "ideologia" com uma função de parcial ocultament o ou disfarce da realidade, operado como fim de melhor pros seguir ou tutelar determinados interesses. Mas is so resulta aindamais claramente, e para nós mais significativa e relevantemente, se analisarmos as doutrinas e os princípios em matéria de contrato elaborados pela ciência jurídica e codificados pelos legis ladores a partir do século passado, no apogeu da hegemonia

\footnotetext{
${ }^{4}$ Art. 1.079. A manifestação da vontade, nos contratos, pode ser tácita, quando a leinão exigir que seja expressa. Art. 1.080. A proposta do contrato obriga o proponente, se o contrario não resultar dos termos dela, da natureza do negócio, ou das circunstancias do caso.
} 
política cultural da clas se burguesa, e que - embora de várias formas contestados e abalados, - ainda hoje continuama exercer a sua influência. (ROPPO, 2009, p. 2930)

Assim, ainda segundo Roppo, para a ideologia liberal, repousada na "mais ampla liberdade de contratar", os contratos derivados do exercício da autonomia da vontade, dentro de um contexto de igualdade formal, representava a própria justiça (p.35).

Todavia, a realidade social, tangenciada pelo avanço do capitalismo e de sua produção, bem como de suas próprias mazelas, como as construídas entre a pobreza e a riqueza, os proprietários e os desafortunados, a classe trabalhadora e a classe patronal, fortemente decorrentes também da ausência do Estado, dizia outra mensagem acerca da justiça meramente formal do positivismo liberal nas relações privadas, inclusive nos contratos.

Com a Declaração Universal dos Direitos Humanos e com a Constituição Federal de 1988, o direito brasileiro começou a se moldar dentro do propósito de um Estado fundado na proteção da pessoa humana, individual e socialmente, mas também da liberdade econômica e do direito de propriedade. A ideologia liberal ainda sobreviveu. Porém, sua pureza ideológica foi desfeita com o tempero da ideologia social (BRASIL. Constituição, 1988, 2014).

Ao se reconhecer, no plano constitucional, por exemplo, a existência de pobres e de desigualdades, foi deitada por terra a falaciosa formalidade da igualdade. Desnudada a desigualdade, a missão passou a ser de tutela e intervenção em prol do estabelecimento de uma igualdade substancial, material, de fato, real.

Logo, traçados os seus contornos, somente é possível a existência de autonomia e, por consequiência, de que esta autonomia seja exercitada de acordo com a vontade, em um cenário de efetiva igualdade. Se esta igualdade inexiste entre consumidores e fornecedores, a conclusão a que se chega é acerca de sua inexistência.

\subsection{AUTONOMIA PRIVADA}

A liberdade e a igualdade ganham novas configurações com a superação do paradigma da autonomia da vontade, através do modelo contratual fundado na autonomia privada, que, em linhas gerais, representa a mitigação das liberdades com a imposição de uma conduta e de um resultado voltado para a justiça material e para a acomodação social do pacto, como se vê na doutrina mais moderna (LISBOA, 2012, p.87-88). 
De fato o modelo contratual fundado na autonomia privada representa a possibilidade de limitação e até mesmo de repressão ao domínio do mais forte, sempre com vistas ao atendimento de um ideal social (função social do contrato), que se notabiliza pela corrente obrigacionista em contraposição à corrente voluntarista, conforme ressoa do enfoque dado por Ricardo Luis Lorenzetti, quando argumenta que

\begin{abstract}
A segunda linha de pensamento, obrigacionista, postula a regulamentação do contrato através de obrigações representativas de valorações coletivas que se impõemaos contratantes. Aqui o direito é um corretivo das as pirações individuais. Considera-se que mesmo os homens mais profissionais estão em dúvida diante daquilo que lhes convémou não, sem contar que a grande maioria, quando sabe o que quer, não pode realiza-lo por situações de hipossuficiência. (LORENZETTI, 1998, p. 543-544).
\end{abstract}

Não obstante o modelo de autonomia privada ser festejado e aceito com conforto na doutrina brasileira, a parte de tal modelo que ainda guarda secções da liberdade como elemento central do contrato, parece não mais se sustentar e coloca em descrédito toda a teoria contratual fundada na autonomia privada, notadamente quando se está a falar dos contratos entre consumidores e fornecedores, ainda que mencionados como espécie contratual onde se mitiga a autonomia privada, conforme se lê nas conclusões de Giselda Hironaka e Flávio Tartuce (HIRONAKA; TARTUCE, 2007, p.77).

Não há dúvidas que o modelo contratual fundado na autonomia privada constitui grandiosa evolução para o tratamento dos contratos de consumo, mas não resolve o problema da inexistência da autonomia dos consumidores.

\title{
3.4 AUTONOMIA EM CRISE
}

Não é possível reconhecer no sujeito consumidor qualquer traço de autonomia. O modelo contratual fundado na autonomia privada ainda considera possível o exercício de alguma autonomia, mesmo que reduzida, mesmo que limitada.

Não há em matéria de consumo lastro algum para escolhas ou decisões, o que seria característica típica da autonomia.

Em verdade o consumidor age inconscientemente, contrata inconscientemente. Pode até ser que por um certo ângulo, seja possível identificar algum elemento volitivo (escolher um modelo, uma cor, um determinado produto, por exemplo). Mas isso somente releva traços de uma racionalidade automatizada, não reflexiva, típica de quem não é livre. 
No entanto, ainda que o consumidor empreendesse uma análise reflexiva, pouco the serviria isso para sua autodeterminação diante do contrato, tanto no que concerne à liberdade de contratar (principalmente), quando no que toca à liberdade contratual. Os contratos são fabricados e postos pelos fornecedores. Não há margem para qualquer interação.

Ir ao supermercado ou à farmácia, parar em um posto de combustíveis, entrar numa padaria são ações completamente desprovidas de qualquer sentido liberto. Não há autogoverno, não há autonomia, efetivamente. Sobre isso, Martin Lindstrom, afirma que:

[...] gostando ou não, todos nós nos comportamos de maneiras que não têmnenhuma explicação lógica ou simples. Is so temacontecido como nunca emnos somundocheio de tecnologia e estresse, no qual notícias de ameaças terroristas, atritos políicos, incêndios, terremotos, enchentes, violência e vários outros desastres nos acometem desde o momento emque sintonizamos o jornal da manhã até a hora emque vamos dormir. Quanto maior é o estresse a que somos submetidos, maior é o medo, a insegurança e a dúvida que sentimos - e maior é a probabilidade de nos comportarmos irracionalmente. (LINDSTROM, 2009, p.25).

Então se a teoria contratual festeja a existência da autonomia, inexoravelmente incidirá em erro na avaliação da justiça contratual. No Estado liberal esse erro decorria da formalização da igualdade e hoje, decorre da crença na existência de autonomia.

Não é possível conceber o ser humano consumidor dos dias atuais como detentor de autogoverno. Ele está em uma condição recursiva de trabalho e consumo, da qual não consegue se desvencilhar. Hannah Arendt afirma que "trabalhar e consumir seguem um ao outro tão de perto que quase constituem um único movimento, o qual, mal termina, tem de começar tudo de novo"(ARENDT, 2013, p.123).

O pensamento de Oscar Wilde, por exemplo, não suscita a menor dúvida acerca de sua crença quanto ao estágio de perda da identidade do homem contemporâneo incluído na cadeia cíclica do trabalho e do consumo, chegando a afirmar que

O homem irá se matar por exces so de trabalho como fim de garantir a propriedade, o que não é de surpreender, diante das enormes vantagens que ela oferece. É de lamentar que a sociedade, construída nes sas bases, force o homema uma rotinaque o impede de desenvolver livremente o que nele há de maravilhoso, fascinante e agradável - rotina em que, de fato, perde o prazer verdadeiro e a alegria de viver. (WILDE, 2003, p.7)

O consumidor nega suas inclinações naturais e sucumbe ao que the é imposto pela indústria: trabalho para consumir, consumo para trabalhar. Modismo, consumismo e descartabilidade para gerar mais demanda e mais produção. Essa lógica perversa do capital 
não é sentida pela sociedade que até se conforta com ela. A impotência para reagir é descrita por Herbert Marcuse (MARCUSE, 1967, p. 17).

Nessa mesma linha, para Bauman

Os mercados de consumos e concentramna des valorização imediata de suas antigas ofertas, a fim de limpar a área da demanda pública para que novas ofertas a preencham. Engendrama satis fação com a identidade adquirida e o conjunto das necessidades pelo qual se define es s a identidade. Mudar de identidade, descartaro passado e procurar novos começos, lutando para renascer - tudo is so é es timulado por es s a cultura como umdever disfarçado de privilégio (BAUMAN, 2008, p..128).

De fato, a pressão exercida pela indústria sobre o consumidor e seu comportamento, especialmente nos tempos atuais, com o reforço da informação em tempo real e do encantamento publicitário e cinematográfico, aniquilam sua autonomia. E, nessa perspectiva, diz Balman que " o que se chamava de "liberdade" nos ambientes pré-modernos não passaria no teste de autonomia segundo os padrões modernos, e, portanto, não seria considerado "liberdade"(BAUMAN, 2008, p.129).

Tais constatações de que o sujeito contratual consumidor não mais detém autonomia, revela a necessidade de que toda a compreensão que se tem hodiernamente sobre os contratos de consumo seja revista radicalmente, como pressuposto de tutela e garantia de justiça nas relações contratuais de consumo.

\section{CRÍTICA AO MODELO CONTRATUAL BRASILEIRO PARA AS RELAÇÕES CONSUMERISTAS}

O Brasil, como já apontado nas linhas anteriores, segue um caminho que aposta na livre iniciativa tendo como contrapesos, dentre outros, a dignidade humana, a justiça social e a defesa do consumidor.

Com isso, a defesa contratual do consumidor ainda leva em conta elementos que legitimam o contrato a partir do exercício da autonomia, deflagrada por uma atividade decisional do consumidor. Essa atividade decisional nada mais é (ou seria) do que a própria liberdade de contratar a que se refere a doutrina (ROPPO, 2009, p. 32).

O Código de Defesa do Consumidor, embora promova uma séria de medidas normativas de proteção, como, por exemplo, a interpretação mais favorável ao consumidor no caso de cláusulas duvidosas, ainda pressupõe a existência de autonomia como elemento formador do contrato, conforme se observa das seguintes transcrições: 
Art. 46. Os contratos que regulam as relações de consumo não obrigarão os consumidores, se não lhes for dada a oportunidade de tomar conhecimento préviode seu conteúdo, ou se os respectivos instrumentos forem redigidos de modo a dificultar a compreensão de seu sentido e alcance.

Art. 48. As declarações de vontade constantes de escritos particulares, reciboseprécontratos relativos às relações de consumo vinculam o fornecedor, ensejand o inclusive execução es pecífica, nos termos do art. 84 e parágrafos. (BRASIL Lei ${ }^{\circ}$ 8.078, de 11 de setembro de 1990, 2014)

Isso termina por conferir ao contrato força obrigacional decorrente do puro formalismo contratual, quando, na verdade, a essência da força obrigatória dos contratos está na pressuposição de que tenha sido concebido a partir de uma ato de liberdade, verdadeira autonomia do sujeito contratante.

Assim, se nos contratos de consumo não se pode conferir ao consumidor o predicado da autonomia, certo é que não se afira a força obrigatória dos contratos a partir da autonomia, mas de outros elementos, como por exemplo, a satisfação das necessidades dos consumidores. Aliás, não é outro o mote dos contratos de consumo senão a satisfação de necessidades.

Vale registrar que os contratos de consumo não se destinam à transferência de riquezas, muito menos às composições jurídicas destinadas à proteção patrimonial. Tais contratos servem, primordialmente para o desiderato de prover o atendimento do consumidor naquilo em que ele é mais débil em relação à indústria: meios de sobrevivência e de provisão de suas necessidades, das mais naturais, como os alimentos, às sociais com a moradia e serviços de comunicação, por exemplo, especialmente na contemporaneidade.

Outro ponto a ser observado para a conclusão acerca da inexistência de autonomia nos contratos de consumo, se deve à ausência de exercício dialógico que também retira do consumidor a liberdade contratual, ou seja, não há espaço para a construção do pacto, não obstante já não ter havido escolha quanto ao próprio ato de pactuar (liberdade de contratar). Nessa linha, Roberto Senise Lisboa, anota que

[...] a padronização de inúmeras espécies de negócios jurídicos e a submissão do hipossuficiente à vontade dos detentores do poder econômico, nos contrato de adesão realizados. Sobredita padrozinação ocasionou não apenas benefícios, como tambémmalefícios ao economicamente mais débil, desprovido de informações e conheciment o para se opor ao instrumento. Nemsequer se viabiliza a discussãodo conteúdo da relação, quase que invariavelmente repleta de cláusulas predispostas. (LISBOA, 2012, p.30)

Diante de tal quadro, com bastante acuidade, Ricardo Luis Lorenzetti aposta na intervenção do Estado, especialmente considerando como vetor protetivo "a manutenção do propósito prático perseguido pelos contratantes." (LORENZETTI, 1998, p. 47-48). E esse 
propósito prático, como defendido aqui, nada mais é do que a verificação de atendimento das necessidades do consumidores.

Aliás, a própria atividade produtiva só se justifica para o fim de fornecimento aos consumidores. Logo, os contratos de consumo não gozam de singularidades ${ }^{5}$, mas de uma homogeneidade finalística, cujos desvios são facilmente identificáveis e perceptíveis para fins de tutela do consumidor.

\subsection{O PROBLEMA NORMATIVO E A PROTEÇÃO DEFICIENTE}

Como visto, a tutela contratual do consumidor baseada na existência de autonomia, ainda que mitigada, e nos efeitos decorrentes do contrato formal derivado de uma manifestação (pseudo) positiva do sujeito consumido em contratar, se materializa em debilidade ou em subdimensionamento da tutela.

Isso porque se passará a considerar o contrato e suas disposições eficazes e produtivas de efeitos jurídicos (obrigações), pelo menos até que o consumidor consiga demonstrar causas que atuem em contrário, como, por exemplo, a onerosidade excessiva decorrente de cláusula abusiva ou de fato superveniente, conforme expresso no Código de Defesa do Consumidor, em seu artigo $6^{0^{6}}$, inciso V (BRASIL. Lei $\mathrm{n}^{\circ} 8.078$, de 11 de setembro de 1990, 2014).

Como o contrato de consumo tem natureza finalista de satisfação das necessidades dos consumidores - porque não é outra sua razão de existir no mundo jurídico e no mundo dos fatos - os efeitos obrigacionais do contrato, especialmente no plano jurisdicional, somente seriam possíveis se demonstrado pelo fornecedor o cumprimento da finalidade contratual, ou seja, que satisfez as necessidades do consumidor.

A satisfação das necessidades do consumidor engloba uma miríade de elementos, dentre os quais importa destacar a equivalência material, como o grande elemento vetor da justiça contratual e a qualidade e quantidade dos produtos e serviços fornecidos. Assim, quando um consumidor fosse cobrado em juízo, por exemplo, caberia ao fornecedor não apenas provar o pacto formalmente, como acontece, mas, também, demonstrar que, além da

\footnotetext{
${ }^{5}$ É importante observar que um traço típico das relações contratuais de consumo da contemporaneidade é a perda ou inexistência de subjetividade. Logo, não estão emquestão os as pectos volitivos do sujeito, como sua vontade ou desejo consciente e governável.

${ }^{6}$ Art. $6^{\circ}$ São direitos básicos do consumidor:[omissis] V - a modificação das cláusulas contratuais que estabeleçam prestações desproporcionais ou sua revisão em razão de fatos supervenientes que as tornem excessivamente onerosas;
} 
formalidade aparente, o pacto cumpriu, acima de qualquer coisa, a satisfação das necessidades do consumidor dentro de uma relação materialmente justa.

\title{
5. A ATUAÇÃO JURISDICIONAL NA TUTELA CONTRATUAL DO CONSUMIDOR
}

Desde o ano de 1973 o Brasil convive com um Código de Processo Civil que é a base para a atuação jurisdicional do Estado. O código de processo nasceu na vigência do Código Civil de 1916, este fundado nos ideais liberalistas, tendo como tônica, no tocante aos contratos, a autonomia da vontade, a força vinculante dos pactos e, portanto, a mínima intervenção do Estado. Evidenciou-se, disso e de toda a tradição positivista, o apego do processo ao império da lei em sentido formal como base para o desiderato da justiça. Prova disso, é o que, logo na exposição de motivos do Código de Processo de 1973, foi externado pelo então Ministro da Justiça, Alfredo Buzaid:

\begin{abstract}
Assimentendido, o proces so civilé preordenado a as segurar a observância da lei; há de ter, pois, tantos atos quantos sejam necessários para alcançar essa finalidade. Diversamente de outros ramos da ciência jurídica, que traduzem a índole do povo através de longa tradição, o proces so civil deve ser dotado exclusivamente de meios racionais, tendentes a obter a atuação do direito(BRASIL, Lei n ${ }^{\circ} 5.869$, de 11 de janeiro de 1973, 2014).
\end{abstract}

Além disso, a cultura jurídica brasileira vigente nos tribunais ainda é dogmática por excelência, e muitas vezes tende à purificação do direito não vendo soluções, respostas ou orientações fora do sistema jurídico fechado, autopoiético. Pior do que isso é a instituição da ditadura das súmulas e precedentes que a pretexto de tornar uniforme o pensamento pretoriano, está aniquilando a subjetividade no processo civil, tão necessária para as singularidades das questões de consumo.

É por isso que Cappelletti e Garth, afirmam que

Nenhumas pecto de nossos sistemas jurídicos modernos é imune à crítica. Cada vez mais pergunta-se como, a que preço e embenefício de quemestes sistemas defato funcionam Essa indagação fundamental que já produz inquietação em muitos advogados, juízes e juristas torna-se tanto mais perturbadora em razão de uma invasão sem precedentes dos tradicionais domínios do Direito, por sociólogos, antropólogos, economistas, cientistas políticos e psicólogos, entre outros. Não devemos, no entanto, resistir a nossos invasores; ao contrário, devemos respeitar seus enfoques e reagir a eles de forma criativa. CAPPELLETTI; GARTH, 1988, p.3) 
O Código de Processo Civil de 2015, embora tenha incorporado as vicissitudes constitucionais tendentes á proteção do mais débil e á prevalência dos Direitos Humanos e dos Direitos Fundamentais, não soará eficaz sem a necessária compreensão fenomenológica, por parte da jurisdição, acerca do consumidor. Destarte, a jurisdição das questões de consumo, especialmente dos contratos de consumo, deve ser das mais dinâmicas possíveis, visto que os fatos e atos de consumo também o são. A lei, por consequência, não tem o fôlego suficiente para acompanhar a evolução e as mutações havidas na sociedade. Nem mesmo o novo Código de Processo tomou foi advento para mudanças mais ousadas. Perdeu-se uma oportunidade.

Nesse sentido, Carlos Maximiliano discorre que

Transformaram-se as situações, interes ses e negócios que teve o Código em mira regular. Surgemfenômenos imprevistos, espalham-se novas ideias, a técnica revela cois as cuja existências ninguémpoderia presumir quando o texto foi elaborado. Nem por is so se deve censurar o legis lar, nem reformar a sua obra. A letra permanece: apenas o sentido se adapta às mudanças que a evolução opera na vida social. $\mathrm{O}$ intérprete é o renovador inteligente e cauto, o Sociólogo do Direito. O seu trabalho reju venesce a fórmula prematuramente decrépita, e atua como elemento integrador e complementar da própria lei escrita. Esta é a estática, e a função interpretativa, a dinâmica do Direito. (MAXIMILIANO, 2003, p.10).

Portanto, a função interpretativa ganha relevo na medida em que permite ao julgador, a partir da compreensão do fenômeno social, como por exemplo a falácia da autonomia do consumidor nos contratos de consumo, operacionalizar a justiça, a verdadeira justiça material e não apenas a justiça formal, dogmática, reativa, sem compromisso com seus efeitos sociais, máxime quando as fontes legais não contribuem significativamente.

É por isso que Enzo Roppo afirma que as relações não ocorrem mais pelo pressuposto da vontade, mas sim pelo imperativo da necessidade, por um "contacto social" e adverte que "a interpretação e a reconstrução conceitual desses fenômenos pode ser variada" (ROPPO, 2009, p.304).

Portanto, o modelo de atuação jurisdicional pós-positivista representa a possibilidade que o intérprete possa avaliar o fenômeno contratual de consumo para bem além do formalismo e do rigorismo técnico de tais instrumentos, alcançando elementos da vida real para o propósito de sua compreensão, a partir do que poderá tutelar com maior acuidade o sujeito consumidor. Essa compreensão foi externada em trabalho de coautoria com o Professor Aloísio Bolwerk, para quem "A corrente pós-positivista propõe a utilização do juízo de adequabilidade realizado pelo Estado interventor aos casos concretos." e avança apostando da atividade interpretativa, para o que: 
A Hermenêutica Jurídica é de salutar importância para compor a abordagem da repersonalização do direito civil, pois permite abertura interpretativa para que outras fontes, a exemplo da linguagem, possam estabelecer a relação dialógica póspositivis ta. O olhar hermenêutico ens eja a aproximação dos conteúdos dos diplomas legais, possibilita a flexibilização de princípios de direito e a ponderação de valores dentro de critérios de razoabilidade/proporcionalidade. (BOLWERK; LORENTINO, 2014, p. 6 e 10).

Portanto, para que se possa considerar qualquer juízo jurídico acerca dos contratos de consumo, é preciso, bem antes, buscar a compreensão deste mesmo contrato enquanto expressão social, típica da contemporaneidade e rica em vicissitudes às quais a lei não têm conseguido atender, razão pela qual o Estado-Juiz passa a exercer o papel de realização da justiça contratual

\section{CONCLUSÃO}

As relações de consumo desempenhadas pelos contratos de consumo são motivadas, para os consumidores, por fatores externos à sua vontade ou poder de decisão

No lugar da vontade, da liberdade ou do autogoverno, o consumidor contrata por necessidades naturais ou sociais, não se podendo falar em autonomia para contratar, muito menos para exercer qualquer discursividade nos contratos, notadamente pela contratação em massa e pela prática dos contratos de adesão, necessários à vazão do grande volume de contratações.

No entanto, o direito brasileiro ainda reconhece parcela de autonomia exercida pelo sujeito consumidor, disso decorrendo algum grau de força obrigatória dos contratos. Trata-se de uma força obrigatória derivada do ato formal a princípio, que pode ser objeto de relativização pelo consumidor nos casos de onerosidade excessiva originada de nulidade de cláusula contratual ou de fato superveniente.

Sem autonomia e considerando o contrato de consumo uma consequência das necessidades inarredáveis do consumidor, os efeitos dos contratos somente podem ser executados pelo fornecedor caso comprove que o pacto propiciou a satisfação das necessidades do consumidor dentro de um contexto que leve em conta a equivalência material, como o grande elemento vetor da justiça contratual e a qualidade e quantidade dos produtos e serviços fornecidos.

A observância de todos esses fatores somente é possível a partir de uma atuação jurisdicional voltada para a tutela do consumidor e lastreada na ideologia pós-positivista que 
propicie a compreensão do fato social e que consiga construir e não apenas aplicar soluções pré-prontas ou pré-concebidas e pré-valoradas na dogmática positivista.

Tal como aconteceu com a descrença na existência da igualdade entre os contratantes pregada pelo liberalismo positivista, talvez seja agora o momento de deitar por terra a mentira da existência da vontade, nos contratos de consumo, o que poderia se concretizar pela estruturação de uma teoria geral dos contratos de consumo. Não pura, mas própria. Não fechada, mas dialógica em fontes e métodos. Enfim, adequada ao fenômeno social que o Direito deve atender.

\section{REFERÊNCIAS}

ARENDT, Hannah. A Condição Humana. Tradução: Roberto Raposo. - 11. ed. - Rio de Janeiro: Forense Universitária, 2013.

AZEVEDO, Álvaro Villaça. Teoria dos Contratos Típicos e Atípicos. 2. ed. São Paulo: Atlas, 2004.

BAUMAN , Zygmunt. Modernidade Líquida.Tradução de Plínio Dentzien. Rio de Janeiro: Zahar, 2001.

BAUMAN, Zygmunt. Vida para Cons umo: a transformação das pessoas em mercadorias. Tradução: Carlos Alberto Medeiros. - Rio de Janeiro: Zahar, 2008.

BITTAR, Carlo Alberto. Contratos Civis. 3. ed. rev. atual.e ampl. por Carlos Alberto Bittar Filho, Márcia Sguizzardi Bittar; Revisão técnica Carla Bianca Bittar. Rio de Janeiro: Forense Universitária, 2006.

BRASIL, Código Civil. Lei $\mathrm{n}^{\mathrm{o}}$ 10.406, de 10 de janeiro de 2002. Disponível em: <http://www.planalto.gov.br/ccivil_03/le is/2002/110406.htm>. Acesso em: 03 nov. 2014.

BRASIL, Constituição (1988). Constituição da República Federativa do Brasil. Brasília, DF, Disponível em: <http://www.planalto.gov.br/ccivil_03/constituicao/constituicao.htm>. Acesso em: Acesso em: 03 nov. 2014.

BRASIL. Código Civil. Lei n. 3.071, de $1^{\circ}$ de janeiro de 1916.. Disponível em: < http:/www.planalto.gov.br/ccivil_03/leis/13071.htm>. Acesso em: 03 nov. 2014.

BRASIL. Código de Defesa do Consumidor. Lei $\mathrm{n}^{\circ} 8.078$, de 11 de setembro de 1990.Disponível em: < http://www.planalto.gov.br/ccivil_03/leis/18078.htm>. Acesso em: 03 nov. 2014.

BRASIL. Código de Processo Civil. Lei no 5.869, de 11 de janeiro de 1973. Disponível em: < http://www.planalto.gov.br/ccivil_03/le is/15869compila da.htm>. Acesso em: 03 nov. 2014. 
CAPPELLETTI, Mauro; GARTH, Bryant. Acesso à Justiça.Tradução Hellen Gracie Northfleet. Porto Alegre: Sergio Antonio Fabris Editor, 1988.

CLARK, Giovani. A proteção do cons umidor e o dire ito e conômico. Belo Horizonte: Interlivros Jurídica, 1994.

FIUZA, César. Dire ito Civil: curso completo. 16. ed. Belo Horizonte: Del Rey, 2013.

HIRONAKA, Giselda Maria Fernandes; TARTUCE, Flávio. O Princípio da Autonomia Privada e o Direito Contratual Brasileiro in Direito Contratual: temas atuais. Coord., Giselda Maria Fernandes Hironaka e Flávio Tartuce. São Paulo: Método, 2007.

LINDSTROM, Martin. A lógica do consumo: verdades e mentiras sobre por que compramos. Tradução de Marcello Lino. Rio de Janeiro: Nova Fronteira, 2009

LISBOA, Roberto Senise. Contratos Difusos e Coletivos. a função social do contrato. 4. ed. São Paulo: Saraiva, 2012.

LORENTINO, Sérgio Augusto Pereira. BOLWERK, Aloísio Alencar . O Dire ito Civil sob a Ótica Pós-positivista: uma nova interpretação a partir da redefinição do conceito de liberdade. In: Roberto Senise Lisboa; Joyceane Bezerra de Menezes. (Org.). RELAÇÕES PRIVADAS E DEMOCRACIA. 1ed.Florianópolis: FUNJAB, 2014, v. , p. 125-142.

LORENZETTI, Ricardo Luis. Fundamentos do Direito Privado. São Paulo: RT, 1998. MARCUSE, Herbert. Ideologia da Sociedade Indus trial. Trad. Giasone Rebuá. - Rio de Janeiro: Zahar, 1967.

MAXIMILIANO, Carlos. Herme nêutica e aplicação do direito. Rio de Janeiro, Forense: 2003.

NAVES, Bruno Torquato de Oliveira. O Direito pela Perspectiva da Autonomia Privada: relação jurídica, situações jurídica e teoria do fato jurídico na segunda modernidade. 2. ed. Belo Horizonte: Arraes Editores, 2014.

PEREIRA, Caio Mário da Silva. Instituições de Direito Civil: Contratos; declaração unilateral de vontade responsabilidade civil. Vol. III, 1. ed. eletrônica. Revista e atualizada por Regis Fichtner. Rio de Janeiro: Forense, 2003.

ROPPO, Enzo. O contrato.Trad. Ana Coimbra e M. Januário C. Gomes. Coimbra: Almedina, 2009.

THEODORO JUNIOR, Humberto. O Contrato e sua Função Social: 3.ed.. Rio de Janeiro: Forense, 2008.

WILDE, Oscar. A Alma do Homem sob o Socialis mo. Tradução: Heitor Ferreira da Costa. Porto Alegre: LP\&M, 2003. 